\title{
Abiud Fonseca*
}

\section{Paulo e os esboços de uma soteriologia que humaniza (GI 3,19-25)}

\author{
Paul and the sketches of a soteriology \\ that humanizes (Gl 3,19-25)
}

\begin{abstract}
Resumo
O presente artigo aborda a proposta soteriológica de Paulo em Gálatas 3,19-25 que sobrepõe a justificação pela fé as obras da lei, pelo seu conteúdo humanizante. Pretende-se reconhecer que a seção 3,19-25 chamada a função da lei, contém argumentos conhecidos pelo público gálata para demonstrar que a lei é transitória, não vivifica, oprime e só aponta um caminho para a real plenitude do ser humano, que se dá através da justificação pela fé. É usada uma síntese da análise retórica e uma revisão crítica do contexto histórico para estabelecer argumentos sistemáticos sobre a soteriologia paulina em Gálatas. Ao final se distingue como o discurso jurídico que usa Paulo em Gálatas alcança debater com a pregação judaizante que objetivava ao ser humano, para sustentar sua proclamação de que a justificação pela fé humaniza ao ser humano em seus distintos âmbitos: corpo-casa-ekklesia, esboçando os rudimentos de sua soteriologia.
\end{abstract}

Palavras-chave: Lei, fé, ser humano, justificação, soteriologia.

\begin{abstract}
The present article deals with the soteriological proposal of Paul in Galatians 3: 9-25, which overlaps the justification by faith for the works of the Law, for its humanizing content. It is intended to recognize that section 3,19-25 called the function of the Law, contains arguments known to the Galatian public to demonstrate that the Law is transient, not vivifying, oppresses and only points a way to the real fullness of the human being, Which is given through justification by faith. A synthesis of rhetorical analysis and a critical revision of the historical context is used to establish systematic arguments about Pauline soteriology in Galatians. In the end it is possible to distinguish how the juridical discourse that Paul uses in Galatians manages to debate with the judaizing preaching that objectified the human being, to support his proclamation that justification by faith humanizes the human being in its different spheres: body-house-ekklesía, Outlining the rudiments of his soteriology.
\end{abstract}

Key words: Law, faith, human being, justification, soteriology

* Mestre em Sagrada Escritura - SEMISUD. Professor de Teologia no Seminário Sudamericano SEMISUD. afonseca@semisud.edu.ec . 


\section{Introdução}

Não há forma de evitar a polarização conceitual que, inevitavelmente, Paulo explicita na carta aos Gálatas, sobre ex érgon nómou (obras da lei) e ex akoês písteos (ouvir com fé), sobre tudo em seu terceiro capítulo.

Esta oposição nos encaminha a distinção do que Paulo estava propondo: uma soteriologia entendida desde a ideia fundante de que o ser humano é sujeito, porque sua justificação não é provocada pelo fazer, mas sim pelo crer (fé) que parte do ouvir, quer dizer, não pela ação que só responde a submissão a uma religião prescritiva, senão por sua condição essencial de ser sujeito que tem a capacidade de abrir-se "a um objeto distinto de si mesmo, em nosso caso, é uma pessoa" (DÍAZ-RODELAS, 2000, p.35): Jesus Cristo. Como disse Bultmann: a pístis (fé) "determina a vida de alguém em sua realidade histórica" (1997, p. 384).

Paulo em Gálatas propõe uma conclusão dominante na soteriologia cristã, que está deve partir e ter como meta, a plenitude da existência do ser humano como pessoa, na pessoa de Jesus Cristo.

A condição humana encontrou sua plenitude e seu cumprimento em uma forma ou outra, como justificação ante Deus no sentido de cumprir-se um direito, o de ir sentindo-se justificado, como determinação da relação com o mundo por meio da autoconsciência religiosa, como liberação para a tarefa ética ou para o ser puramente pessoal. Trata-se sempre de que o ser humano do homem se realiza e chega a sua plenitude graças a Jesus (PANNENBERG 1974, p. 62-63).

Paulo, empurrado pela frustração implicada pelo aviso de que os Gálatas, sujeitos de sua missão, sucumbiram ante os argumentos dos judaizantes, responde veemente articulando os prolegômenos de sua soteriologia, mas adiante plenamente tratada na Carta aos Romanos.

Na seção da carta aos Gálatas 3,19-25, procura-se contra argumentar a funcionalidade da lei no processo de justificação e consequente aproximação do ser humano a Deus, através de ilustrações propostas pelo apóstolo, que são conhecidas pelos irmãos de galácia, por serem representações da vida e fala cotidiana daquele espaço.

No presente artigo, pretendo fundamentar a ideia de que a passagem em questão se move semanticamente na intenção de responder a pergunta inicial: Para que serve a lei? Que viria a ser uma espécie de pergunta retórica cujo objeto em si é destacar o caráter categórico da justificação pela fé; estabelecendo-se o princípio soteriológico de que a fé em Jesus Cristo humaniza a pessoa permitindo-lhe viver sua plenitude de ser, contrariamente a opressão que exerce a lei. 


\section{A unidade literária}

A continuação estabeleço alguns posicionamentos sobre a análise retórica da carta aos Gálatas, com o fim de distinguir a particularidade da seção de 3,19-25, baseado em algumas das abundantes aproximações eruditas como os clássicos estudos de Betz (1979), cuja tese central preconiza que a carta aos Gálatas é uma carta apologética com as características retóricas de um discurso forense o genus iudiciale (dikanikón génos), posição seguida por Becker (1996), entre outros estudiosos ${ }^{1}$.

Gálatas 3,19-25 é um paragrafo que forma parte de um apartado mais amplo, no qual Paulo exibe argumentos para respaldar a tese proposta anteriormente. No bloco compreendido entre 3,1-4,31, Paulo ensaia demonstrações discursivas sobre a ineficácia das obras da lei, e ademais procura convencer aos Gálatas "de que já foram justificados pela fé, abençoados por Deus, herdeiros de uma linhagem de pessoas livres; e tudo isso independentemente da lei" (TÁMEZ, 2003, p. 905). 0 apartado onde se manifesta o assunto medular estende-se entre Gálatas 2,15-21. Portanto, a seção a ser examinada depende dela.

Assumindo que toda pretensão de interpretar o texto poderia estar condicionada pelas suspeitas e interesses de cada interprete, considero que a estrutura definida por E. Cothenet (1981, p. 36), semelhante à estabelecida por Betz (TOLMIE, 2004, p.14) quem distingue a seção de 3,19-25 como parte do probatio ${ }^{2}$ que abarca do 3,1 ao 4,31; permite destacar a proposta da seção que chamarei: A função da Lei. Então, os parágrafos citados poderiam organizar-se do seguinte modo:

2,15-21: tese de Paulo na carta - o antagonismo entre as obras da Lei e a justificação pela fé

3,1-4,31: Os argumentos que sustentam a tese 2,15-21

3,1-5: Apóstrofe de reclamo aos Gálatas

3,6-18: Argumento bíblico: A promessa a Abraão

3,19-25: A função da Lei

3,26-29: Herdeiros de Cristo

4,1-7: Ser filho de Deus

4,8-20: Fazendo memória

4,21-31: Argumento bíblico: Sara e Agar

Para ter um panorama contemporâneo sobre as investigações retóricas de Gálatas, recomendase revisar o estado de arte da dissertação de doutorado de Tolmie (2004, p.13-33) apresentada a University of the Free State Bloemfontein South Africa.

2 É uma parte do discurso forense que apresenta os argumentos que confirmam o exposto na tese. 
Gálatas 3,19-25 é um pequeno parágrafo dentro de um grande postulado em favor da justificação pela fés ${ }^{3}$ que, portanto, depende das bases semânticas que dominam em 2,15-4,31. Porém, apesar de que exista uma unidade temática em todo o apartado, as seções se distinguem pelos giros estilísticos que toma o autor para argumentar sua posição. Ademais, não é possível perder de vista as seções que procedem e sucedem a 2,14-4,31, para um entendimento pleno dos argumentos paulinos sobre a oposição entre obras da Lei e justificação pela fé.

A seção chamada de a função da Lei distingue-se das anteriores porque começa com uma pergunta retórica que será contestada de maneira argumentativa com "alguns exemplos tomados de seu contexto” (TÁMES, 2003, p. 905). O giro que diferencia esta seção, não é temático; mas estilístico.

A primeira seção do apartado 3,1-4,31 começa com a apóstrofe compreendida em 3,1-5, onde é notória a frustração do apóstolo pelo pouco valor que dá os Gálatas a experiência vivida. Paulo, através de uma série de perguntas retóricas inicia sua argumentação, provocando o público gálata leitor a revisar sua experiência inicial de fé. Depois disso, continua a seção do 6-18 onde o recurso estilístico que se usa é a argumentação bíblica ${ }^{4}$, tomando como base de diálogo a história de Abraão.

Como foi dito, um giro estilístico marca o inicio da seção a função da Lei. Outra vez o autor recorre à pergunta retórica, mas neste caso, não é para confrontá-los com a experiência, mas para argumentar contra a Lei usando imagens tradicionais.

Na seção 3,23-29 notoriamente o autor faz uma mudança de pessoa, a segunda no plural, a diferença da primeira pessoa no plural usada na função da Lei, além disso, a forma de escrever é mais bem sintética, começando o uso de analogias como a de "herdeiros segundo a promessa" $(3,29 b)$. Na seção 4,1-7, se privilegia o uso de analogias, "porque é um tipo de argumento que pode ser muito efetivo" (TOLMIE, 2004 , p. 136), sobre tudo porque não perde de vista o sentido jurídico de sua argumentação. A partir de 4,8 começa outra sequência de explicações apelando Paulo a seu testemunho para seguir propondo

Pode-se considerar a carta aos Gálatas como o primeiro documento bíblico em tratar amplamente sobre a justificação pela fé (BECKER, 1996, p. 345-362).

J. Becker em consonância com as investigações de Betz estabelece até 3 seções nesta parte: 3,69; 3,10-14 e 3,15-18. Observando que só nas duas primeiras seções são feitas "seis citações em torno a figura de Abraão" (BECKER, 1996, p. 332). 
perguntas desafiantes. Os argumentos finalizam em 4,21-31 com outras provas das escrituras que remetem a história patriarcal de Sara e Agar.

\section{Questões de contexto}

Sobre o contexto da carta, também se escreveu muito, no entanto, acho necessário recordar descritivamente alguns elementos particulares que podem aportar a análise sobre a justificação pela fé em 3,19-25. Considerando que a tese paulina não é somente contrapor duas perspectivas soteriológicas, mas estabelecer como princípio soteriológico fundamental o valor do ser humano como humano, estabeleço que na realidade dos Gálatas existiam espaços para a humanização-desumanização da pessoa. De acordo com Gil Arbiol, o corpo (indivíduo), a casa e a cidade (2008, p. 283-305) são elementos distinguíveis na cimentação sócio-antropológica que Paulo ${ }^{5}$ tem na formação de suas comunidades; embora creia que não são somente fundamentos para esta dimensão política, mas também para o reconhecimento de sua soteriologia, a que indefectivelmente também tem conotações políticas.

Corpo-indivíduo: A opressão e a escravidão na sociedade de Galácia

Um dos paralelos que Paulo sustenta em seu discurso sobre a justificação da fé, é a opressão que significa o agir sob a Lei, tendo a escravidão como sistema desumanizante.

Não existe dúvida de que a escravidão foi uma condição vigente na sociedade de galácia, no século I, ainda que não como em outras sociedades romanas.

Prosseguindo de tribos gálatas não sujeitas a escravidão, podemos supor que poucos receptores da carta eram ou foram escravos... A composição social das cidades gálatas não diferencia excessivamente de outras cidades do império, exceto, provavelmente por uma menor quantidade de escravos (RAMÍREZ, 2006, p. 14-15).

Os postulados aristotélicos sobre cidadania, provavelmente geraram um substrato ideológico para a prática da escravidão, assumindo-a como normal na sociedade greco-romana. "Para Aristóteles,... o escravo não é um homem, mas uma espécie de instrumento animado (soma, organón). 0 escravo nasceu para a servidão o mesmo que o cidadão para

Também de Aristóteles, mas em Paulo o conceito de cidade está mais ligado a vida comunitária, quer dizer, a comunidade de crentes ou ekklesía (assembleia-igreja). A diferença de Aristóteles quem entende a casa como espaço familiar-doméstico e a ekklesía como espaço político, para Paulo a ekklesía também é a casa (GIL ARBIOL. 2008, p. 292). 
a liberdade" (COTHENET, 1985, p. 78). Na vida comunitária paulina, a ruptura de diferenças sociais foi a dimensão política que serviu como fundamento para sua eclesiologia libertadora. Assim como também em sua soteriologia qualquer forma de opressão humana não podia ser congruente com a justificação pela fé.

Se aceitarmos a posição que sustenta que a carta está dirigida aos membros da etnia dos gálatas ${ }^{6}$, recordaremos sua história política conflitiva onde a opressão foi um denominador comum. Primeiro, a conquista do império Romano e o fim de um sistema de governo gálata de aproximadamente três séculos, no ano 25 a.C., com a morte do rei Amyntas; que deu início a um processo de adoção obrigatória da cultura greco-romana. Consequentemente, os estragos desta subordinação foram pesados para as classes empobrecidas e marginalizadas da Galácia, "e inclusive os ricos das cidades. 0 passo das tropas militares era devastador" (TÁMEZ, 2003, p. 896).

A opressão é um estado ao qual se alcançou devido a eventos conflitivos, embora seja certo que o povo é quem sofre opróbio, no fim, o indivíduo, que não só forma parte do povo, mas que é o próprio povo, será o que vivera neste estado, e necessite de um projeto libertador. Paulo entende que a lei é para o indivíduo um sistema de opressão, como a escravidão, portanto desumanizante, e não provê uma alternativa de liberdade.

\section{Casa: A situação socioeconômica dos habitantes de Galácia}

A oikía u oîkos (casa) era o espaço vital. De acordo com Gil Arbiol, para os escritos de Paulo a casa excede a ideia de ser somente um âmbito onde vive uma família, mas é representação da vida humana mesma em pelo menos três dimensões desta: teológico - casa como espaço de construção da vivencia de fé (ekklesía), social - casa como espaço para a vida familiar, e físico - o corpo físico do crente como casa (2008, p. 285-287).

A casa, em sua dimensão social, teve que suportar as repercussões de uma realidade política complicada: tanto a educação como a situação socioeconômica do morador médio de Galácia não era em extremo calamitosa, a exceção dos grupos marginalizados próprios da estratificação social romana, que nem tinham casas. Não se tratava de

Posição mais aceita pelos estudiosos, diferente da outra "hipótese do sul de Galacia", que prefere entender que os destinatários são os habitantes da província romana do mesmo nome. 
uma sociedade intelectual, tampouco de uma zona com grandes metrópoles, nem de um mercado altamente produtivo: mas sim de um espaço onde o grupo étnico assentado faz alguns séculos, alcançou manter-se graças ao gado e a agricultura, atividades principais que lhes permitia sustentar a família, apesar da submissão ao Império Romano. A metade das pessoas tinha ocupação ou pequenas propriedades, ainda que sua inclusão a cultura greco-romana fosse tardia, no século I d.C. muitos foram admitidos dentro do status de cidadãos romanos ${ }^{7}$, o que lhes concedia participar dos privilégios dessa situação.

Consideremos duas coisas: uma, a família gálata tinha desenvolvido um grau de cultura, o que certamente desafiou o apóstolo a postular vastas ideias sobre a salvação, usando enfoques jurídicos e confrontando-a dialogicamente com sua situação vital. Dois, a família em Galácia teve que enfrentar o dilema de sua etnia, submissão ao poder, processos de enculturação, religiosidade, entre outras conjunturas, para continuar sendo um espaço de construção de vida. A isso, o advento da pregação judaizante alentou a perda desta possibilidade porque exigia a aquisição de novas práticas excludentes como a circuncisão e suas implicações favoráveis com a hegemonia patriarcal. Por isso, ante a alternativa vivificadora da casa, sobretudo quando é espaço comunitário de fé, Paulo estabelece que a Lei é incapaz de vivificar (Gálatas 3,21).

Cidade-Eklesía: 0 encontro entre a comunidade cristã gentil de Galácia e a tradição judaica.

Para Paulo, as ideias políticas de construção da pólis (cidade) segundo Aristóteles puderam encaixar na experiência de construção da ekklesía ${ }^{8}$. No entanto, quando a ekklesía vai perdendo sua capacidade de ser comunidade reconciliadora, se converte em um espaço para a opressão humana, questão que denuncia Paulo sobre a consequência do encontro com os judaizantes, em Gálatas.

Apesar da escassa informação sobre a vida da Galácia no século I d.C., desde uma revisão do texto neotestamentário, podemos estabelecer que a visita missionária do apóstolo Paulo gerou o início de comunidades em torno ao seu testemunho sobre Jesus Cristo, quer

\footnotetext{
“Nos tempos de Octavio Augusto algumas famílias gálatas já tinham adquirido a cidadania romana. Quando Paulo chega a Galácia, é provável que este número de cidadãos romanos teria aumentado" (RAMÍREZ, 2006, p.15).

8 Entre as funções que tem a cidade, Aristóteles reconhece: a preparação e oferta de comidas comuns, a regularização do matrimônio, os mecanismos de controle dos desvios, a resolução de conflitos entre as classes sociais e o acesso dos indivíduos a cidadania. Estas características aparecem nas cartas de Paulo referente às ekklesía" (GIL ARBIOL, 2008. P. 293).
} 
dizer que surgiram igrejas sob a influência de uma tradição judaica que estava tomando certos giros com o cristianismo nascente. Se em Galácia existiu anteriormente alguma aproximação ou inclusive adoção do judaísmo, não há precisão ${ }^{9}$, embora pudesse ser provável pela frequência das migrações, e pela forma como os membros gentis ${ }^{10}$ das comunidades cristãs não recusaram a pregação judaizante que exige práticas extremas, como a circuncisão.

A carta não é um informativo sobre o encontro cultural entre os gálatas ${ }^{11}$ ou os cidadãos romanos de Galácia ${ }^{12}$ com o judaísmo, pois seria muito pretencioso aludir ao acontecimento da chegada de Paulo, e logo dos judaizantes, como o início de um processo de enculturação judaica, ou judeu-cristã. Mas se deixa sentada a experiência vivida no micro espaço das famílias e comunidades que adotam a fé judeu-cristã de Paulo e seu posterior encontro com os judaizantes, quem lhes impõe suas práticas culturais-religiosas, com o fim de corrigir a evangelização equívoca de Paulo.

A respeito, podemos apontar que a irrupção dos judaizantes na ekklesía dos gálatas inaugurou uma espinhosa situação de adoção de uma fé ou de uma cultura, principalmente pela obrigada observância da Lei, que ao invés de suscitar a edificação da comunidade como corpo, permitiu a exclusão de pessoas, que seguramente levaram Paulo a emitir a esplêndida e categórica declaração de Gálatas 3,28.

\section{Análise do discurso}

Como foi dito, a pretensão paulina em Gálatas 3,1-4,31 é argumentar a favor do propósito humanizante da justificação pela fé, em contraposição com a desumanização que pode levar ao entendimento de que a salvação é pelas obras da Lei. Na seção da função da Lei $(3,19-25)$

\footnotetext{
9 A respeito: "ainda que não temos, por outro lado, evidencias de assentamentos judaicos naquela região no tempo de Paulo, talvez devamos supor que se trata de gentis que, já antes de sua conversão a Cristo, mantiveram relações com o judaísmo" (RAMÍREZ, 2006, p. 16).

10 "através da carta se pode assegurar que os destinatários eram gentis convertidos ao cristianismo $(\mathrm{Gl} 4,8)$. Como o texto da carta reflete um bom manejo da retórica, cabe supor que nas comunidades cristãs dos gálatas havia membros do setor médio, educados na cultura grega" (TÁMEZ, 2003. P. 898).

11 Do Norte da Galácia. Imigrantes celtas que chegaram da Europa a Asia Menor no século III a.C.. "O nome Galatai é a forma mais recente de keltai. Designa os habitantes da zona... que se estabeleceram aqui pouco antes do 280 a.C." (MARXSEN, 1983. 55).

12 Do sul de Galácia. Residentes do país galáctico que, logo da morte de seu rei "em 25 a.C., o país se converteu em uma província romana" (MARXSEN, 1983, p. 55).
} 
a argumentação toma certos matizes, através de perguntas e sentenças que o apóstolo escreve, buscando que o leitor gálata confronte sua prática atual de fé, que foi influenciada pela pregação judaizante, com a aprendida na evangelização paulina.

O centro temático está estabelecido pela pergunta inicial tí oûn jo nómos (para que serve a lei?) onde Paulo já manifesta, com ironia, suas dissonâncias com as ideias judaizantes sobre o valor da lei. Esta pergunta também se pode compreender como uma espécie de transição entre a conclusão a argumentações anteriores, e a inauguração de novas.

Recordamos que, si bem é certo, ao serem gentis, os gálatas não conheciam plenamente a Lei de Moisés, nem as tradições veterotestámentárias, também é válido assumir que pela evangelização paulina e o trabalho missionário dos judeu-cristãos haviam ampliado seus conhecimentos sobre as escrituras, por isso Paulo discutirá confiadamente usando ilustrações conhecidas na tradição judaica e judeu-cristã ${ }^{13}$. Também porque não se deve descartar a ideia de que a epistola estava indiretamente dirigida aos judaizantes, pela evidente disputa contra eles.

Na seção a função da Lei, Paulo usa várias sentenças que são muito confusas ${ }^{14}$ com possíveis interpretações variadas e até contrarias, no entanto é claro que se trata de uma seção que argumenta contra o valor da lei, Pra isso posso distinguir até quatro argumentos.

\section{A Lei é inferior por ser transitória}

Não é mais possível crer na Lei de Jesus Cristo, quem é a consumação da promessa divina de salvação. Porque definitivamente, Jesus Cristo é o caminho humanizante de uma salvação que se alcança por acreditar nele como aquele que encerra a plenitude da promessa; enquanto que a lei foi transitória porque ante sua proposta o que imediata e consequentemente provocou foi sua transgressão.

Isto se evidencia na polêmica sentença que segue a pergunta inicial, que inclusive poderia induzir a valorações opostas, dependendo de sua leitura: tõn parabáseon jarín prosethéte (agregada devido a $o$ com o propósito das ${ }^{15}$ transgressões). Como estabelecem a maioria das

\footnotetext{
13 “Nunca vamos perder de vista que os adversários combatidos por Paulo são cristãos e não judeus propagandistas... isso que dizer que a argumentação de Paulo não pode ter valor além do ponto de vista cristão" (COTHENET, 1981, p. 10).

14 Foi defendido inclusive que em certas partes Paulo não se expressa de maneira clara (Dunn, Tolmie).

15 "It is well known that carín can mean either 'because of' or 'for the purpose of'" (TOLMIE, 2004, p. 172, tradução nossa).
} 
exegeses contemporâneas ${ }^{16}$, o significado da frase, mais congruente com o resto do discurso, é o que propõe que as transgressões se "produzem precisamente pela existência mesma da lei" (DÍAZ_RODELAS, 1994, p. 51). E este ájris jôu élthe tò spérma jô epéggeltai (até que viesse a semente que foi prometida).

A transitoriedade da Lei não pode resolver a imperfeição e crise humana nos três espaços definidos na visão política de Paulo: indivíduo-casa-ekklesía, porque, como Paulo esteve argumentando em toda a grande seção, a lei só busca que o ser humano atue baixo sua imposição, quer dizer que a lei não é um sujeito que brinda a possibilidade de que se encontre nela a plenitude de ser ao sujeito, mas é objeto porque ela mesma é obra de um sujeito, como se sentencia em 3,19b foi ordenada por meio de anjos en jeirí mesítou (na mão de um mediador), e só alcançou que o sujeito atue baixo imposição, gerando nele transgressão. Isto é, o sujeito foi objetivado, desumanizado.

Mas também, o indivíduo pode encontrar sua plenitude de ser quando chegue desde um spérma (semente) humano, desde uma existência em si mesma, diferente da Lei que veio por um mediador, o cumprimento da promessa divina de redenção. Assim o sujeito, poderá construir plenamente seu corpo pessoal (indivíduo), social (casa) e teológico (ekklesía). "A pregação e a teologia do apóstolo tendem continuamente ao objetivo de fazer que o homem, frente a Deus, compreenda-se e com isso reflexione sobre sua situação e a de sua vida em meio ao mundo" (BORKAMM, 1997, p. 170).

\section{A Lei é inferior porque não vivifica}

Em 3,21 se estabelece uma seguinte pergunta retórica jo oûn nómos katá tõn epaggelión (Logo, a Lei é contrária às promessas...?). Surpreendentemente o apóstolo responde: mè gévoito (jamais, de modo algum), que nos induz a ler como uma espécie de incongruência a tudo o que se veio propondo. No entanto, se entendemos que a realidade da Lei não é indiscutivelmente uma equivocação, mas uma espécie de capítulo antes da chegada do cumprimento pleno da promessa, poderíamos compreender que há muita razão na frase.

Esta transitoriedade a faz inferior a fé em Jesus Cristo, porque a lei não pode, sendo perecível, vivificar ao ser humano. Como disse 3,21b: ei gàr edóthe nómos jo dunámenos zopoiêsai (porque se a lei

16 Como Schlier, Betz, Brucem Díaz-Rodelaz, entre outros. 
dada pudesse vivificar), então a justificação do ser humano viria pela Lei, no entanto esta possibilidade acaba com a circunlocução exposta. "A Lei não pode dar vida; ao menos não pode dar a vida em plenitude" (DÍAZ-RODELAS, 1994, p. 60), no entanto, a fé em Jesus Cristo sim.

Por isso Paulo em 3,1 alude aborrecido ao entender a fascinação que os irmãos da Gálacia proporcionaram as artimanhas dos judaizantes, porque a dimensão do ser humano como sujeito entra em uma total desvirtuação ao aceitar que é pela lei que o ser humano alcança vida plena.

Para argumentar mais, Paulo faz um exercício hermenêutico, confiando que os Gálatas entendem sua retórica, porque conhecem a escritura veterotestamentária e as regras do discurso forense: allà sunékleisen je grafè tà pánta jupò jamartían (mas aprisionou toda a escritura sob o pecado). De tal modo, a Lei é incapaz contra a realidade humana que fez cair toda sua existência sob o domínio do pecado, o qual está testemunhando pela mesma escritura. Então, só pela fé haverá a viabilidade de salvação de um cenário completamente alienado.

0 que foi dito por Paulo obriga o leitor da galácia a confrontar-se com o que está vivendo em seu próprio contexto. Retornando a proposta de Gil Arbiol, aceitar a Lei é favorecer a construção de uma vida plena nas três dimensões políticas da vida do ser humano (corpo, casa, ekklesía)? Definitivamente não, a lei não alcança poder para isso.

\section{A Lei é inferior porque escraviza}

Em 3,23, Paulo começa a articular uma série de argumentos relacionados com a opressão-escravidão, que amplamente os desenvolve na segunda seção.

A referência a este estado de vida, não é fortuita nem abstraída de seu contexto. Mas bem, parece que o apóstolo toma uma das formas mais aberrantes de perder a condição essencial humana para alegorizar contra a lei, sabendo que os gálatas estão experimentando uma situação constante de opressão e que sabem o que significa a falta de liberdade.

A vida bob a Lei implicaria aceitar que a justificação ante Deus se dá através da prática de alguma forma de opressão, como faziam as religiões pagãs de onde procediam os gálatas ${ }^{17}$, assunto decisivamente recusado pelo evangelho de Paulo, entre outras coisas, porque métodos como a circuncisão eram uma espécie de paralelo, imposto pela Lei, aos costumes idólatras. Ademais, na casa-ekklesía, as comunidades paulinas

17 Questão que será amplamente tratada em Gálatas 5. 
começaram a experimentar vivencias contrárias aos paradigmas sociais desumanizantes do contexto greco-romano, como a escravidão. "Através do amor fraterno e da aceitação dos escravos em plena comunhão dos redimidos de Cristo, a Igreja primitiva marcou uma nova direção" (SCHNACKENBURG, 1989, p. 299). Então a pregação judaizante de aceitação da Lei não poderia ter encontrado espaço em uma comunidade que começou a viver sua liberdade a partir do ouvir com fé.

\section{A Lei é inferior porque nos guiou a fé}

Qual é a função da lei? Fazer o que o escravo faz paidagogòs (ayo), que não é o mestre (didáskalos), mas o encarregado de acompanhar o estudante a seu centro de estudos. Esta figura conhecida pelos gálatas exemplifica vastamente o que Paulo argumenta sobre a Lei. Não é que esta seja completamente deplorável, nem demoníaca, mas serve para aproximar-nos a Deus, porque em sua qualidade desumanizante por retirar do ser humano a capacidade de viver em liberdade, também gera nele uma busca inesgotável de sentido que só será ultimamente respondida em Deus.

Mesmo que tenha caído em poder do pecado e se afastado sensivelmente do desígnio de divino, Deus não deixa a lei de sua mão... A lei (nomos), mesmo que de maneira indireta e muito paradoxal, está a serviço da vontade salvadora de Deus, precisamente em quanto que recusa e não dá passo aa vida. Isto é o que quer significar o dito paulino que chama a lei de 'pedagoga até Cristo' (BORNKAMM, 1997, p. 179).

Paulo conclui esta seção com uma sentença axiomática: elthoútes dè tês písteos oukéti jupò paidagogóv esmen (mas a fé chegou, não estamos mais sob um tutor). A fé devolve ao ser humano a capacidade de ser pessoa, porque de partida, nossa salvação se gesta na busca consciente do modo supremo da pessoa, mas, por sua vez, já está modelando nossa busca da plenitude de ser, como pessoas: Jesus Cristo.

\section{Conclusão}

Para que serve a Lei? Para darmos conta, como disse Pannenberg: que "a humanidade do homem se realiza e chega a sua plenitude em Jesus", não por meios que impliquem alguma forma de opressão.

Se partirmos do fato de que a essência mesma de Deus é seu amor, como o aborda Jean Luc Marion quando vai além da analogia 
do sujeito para explorar o ser de Deus e entendê-lo mais bem desde a perspectiva do dado ${ }^{18}$ (MARION, 2010), é impossível pensar que sua redenção venha pela imposição ou, pior ainda, pela desumanização do ser humano. Então a soteriologia deve ter como fim que o ser humano alcance sua plenitude de ser, em Deus, através de Jesus Cristo.

No século I d.C., Paulo já tinha estabelecido o esboço de uma soteriologia que transcendeu a tradição de um judaísmo que não pôde entender que sua religião exigia do ser humano o fazer, mas não seu ser. Assim, os judeus simpatizantes do cristianismo acreditaram que a mensagem de Jesus podia dar-lhes certa liberdade, mas se recusaram a abandonar a ideia de que a lei devia continuar dizendo ao ser humano o que tinha que ser, impedindo-lhe que realmente seja. Por isso, o apóstolo debateu vigorosamente com aqueles que entorpeciam o propósito de sua pregação sobre a fé, à mesma que sofreu uma série de rupturas em seu encontro com o mundo gentil. Gálatas 3,19-25 sentencia com firmeza que só a fé em Jesus, não como o homem de Nazaré, mas como o Cristo, pode Justificar.

Ao Jesus Histórico Paulo simplesmente o identificou com o filho preexistente de Deus, interpretando a crucificação como um ato divino de intenção salvadora e significado cósmico. Quanto mais Paulo pregava de acordo com esses critérios, parecia claro que seu evangelho helenizado estava mais perto da verdade - segundo ele a entendia - que da restrição imposta pela estreita visão do cristianismo judaico, se em verdade podia chamar-se assim (JOHNSON, 1999, p.59).

A justificação pela fé permite ao ser humano não só encontrar-se com o Deus dado, mas fazer de seu corpo casa para este Deus, que em essência é amor. Assim, sua casa se converterá em espaço vivificante onde o amor deve promover rupturas socioculturais e converter-se em ekklesía ou comunidade para viver a fé.

Assim, Paulo esboça os rudimentos de uma soteriologia que humaniza, base para nossa teologia cristã, estabelecendo o caráter humanizante da justificação pela fé, porque se trata da opção divina por amar o ser humano e querer sua realização plena pela participação de uma vida livre de qualquer tipo de opressão. Para isso, a pessoa, em sua condição de ser humano ouve e crê, não só fazendo o que deve fazer, mas abrindo-se e participando daquele em quem colocou sua fé: Jesus Cristo, cuja vida lhe dará ao ser humano a possibilidade de ser constantemente mais humanizado.

18 "Deus salva o dom precisamente por que não é, por que não tem que ser. Pois o dom não tem de
entrada que ser, mas jogar-se em um abandono que é o único que o faz ser" (MARION, 2010, p.19). 


\section{Referências}

BECKER, J. Pablo el apóstol de los paganos. Salamanca: Ediciones Sígueme, 1996.

BETZ, H. D. Galatians: A Commentary on Paul's Letter to the Churches in Galatia. Philadelphia: Hermeneia Fortress, 1979.

BORNKAMM, G. Pablo de Tarso. 5. ed. Salamanca: Ediciones Sígueme, 1997.

BULTMANN, R. Teología del Nuevo Testamento. 3. ed. Salamanca: Ediciones Sígueme, 1997.

COTHENET, E. La Carta a los Gálatas: CB 34. Navarra: Editorial Verbo Divino, 2003.

COTHENET, E. San Pablo en su tiempo: CB 26. 4. ed. Navarra: Editorial Verbo Divino, 1985.

DÍAZ-RODELAS, J. M. Pablo y la ley: La novedad de Rom. 7,7-8,4 en el conjunto de la reflexión paulina sobre la ley. Navarra: Verbo Divino, 1994.

GIL ARBIOL, C. La dimensión política de las comunidades paulinas: cuerpo, casa y ciudad en Aristóteles y Pablo. In: BERNABÉ, C y GIL, C. Reimaginando los orígenes del cristianismo: Relevancia social y eclesial de los estudios sobre orígenes del cristianismo. Navarra: Editorial Verbo Divino, 2008, p. 283-305).

JOHNSON, P. La historia del cristianismo. Barcelona: Ediciones B, 2010.

MARION, J. L. Dios sin el ser. Pontevedra: Ellago Ediciones, 2010.

MARXSEN, W. Introducción al Nuevo Testamento: Una iniciación a sus problemas. Salamanca: Ediciones Sígueme, 1983.

PANNENBERG, W. Fundamentos de Cristología. Salamanca: Ediciones Sígueme, 1974.

RAMÍREZ, F. Gálatas y Filipenses. Navarra: Verbo Divino, 2006.

SCHNACKENBURG, R. El mensaje moral del Nuevo Testamento: Tomo 1 De Jesús a la Iglesia primitiva. Barcelona: Editorial Herder, 1989.

TÁMEZ, E. Carta a los Gálatas. In: LEVORATTI, A. Comentario Bíblico Latinoamericano: Nuevo Testamento. Navarra: Editorial Verbo Divino, 2003, p. 895-912.

TOLMIE, D. F. A rethorical analysis of the letter to the Galatians. 2004. 248p. Dissertação: Departamento de Griego. Faculty Of Humanities At The University Of The Free State Bloemfontein, SOUTH AFRICA. Bloemfontein, Sudáfrica. Disponível em: http://scholar.ufs.ac.za:8080/xmlui/bitstream/handle/11660/1730/ TOLMIEDF.pdf?sequence=1. Visitado em: 02 de maio de 2017.

Traduzido por Leide Jane Soares dos Santos. 